\title{
Transition-Metal-Free Synthesis of C3-Arylated Benzofurans from Benzothiophenes and Phenols
}

DOI:

10.1021/acs.orglett.8b03267

\section{Document Version}

Accepted author manuscript

Link to publication record in Manchester Research Explorer

\section{Citation for published version (APA):}

Yang, K., Pulis, A. P., Perry, G. J. P., \& Procter, D. J. (2018). Transition-Metal-Free Synthesis of C3-Arylated Benzofurans from Benzothiophenes and Phenols. Organic Letters, 20(23), 7498-7503.

https://doi.org/10.1021/acs.orglett.8b03267

\section{Published in:}

Organic Letters

\section{Citing this paper}

Please note that where the full-text provided on Manchester Research Explorer is the Author Accepted Manuscript or Proof version this may differ from the final Published version. If citing, it is advised that you check and use the publisher's definitive version.

\section{General rights}

Copyright and moral rights for the publications made accessible in the Research Explorer are retained by the authors and/or other copyright owners and it is a condition of accessing publications that users recognise and abide by the legal requirements associated with these rights.

\section{Takedown policy}

If you believe that this document breaches copyright please refer to the University of Manchester's Takedown Procedures [http://man.ac.uk/04Y6Bo] or contact uml.scholarlycommunications@manchester.ac.uk providing relevant details, so we can investigate your claim.

\section{OPEN ACCESS}




\title{
Transition Metal-Free Synthesis of C3-Arylated Benzofurans from Benzothiophenes and Phenols
}

\author{
Kevin Yang, Alexander P. Pulis, Gregory J. P. Perry, David J. Procter* \\ School of Chemistry, University of Manchester, Oxford Road, Manchester M13 9PL, U.K. \\ Supporting Information Placeholder

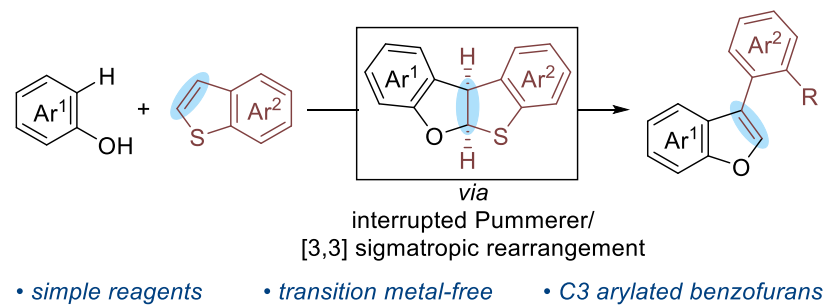

\begin{abstract}
We report a transition metal-free synthesis of benzofurans from benzothiophenes and phenols that exploits the unique reactivity of sulfoxides. Through a sequence involving an interrupted Pummerer reaction and [3,3] sigmatropic rearrangement, phenols can be combined with readily accessible yet synthetically unexplored benzothiophene S-oxides to provide C3arylated benzofuran products. The products from this approach can undergo subsequent functionalization to gain access to a range of important benzofuran derivatives.
\end{abstract}

The benzofuran motif is a key structural unit found in a variety of functional molecules, from naturally occurring bioactive compounds to man-made organic electronics. ${ }^{1}$ Demand for this important sub-unit has resulted in a range of methods for its construction. ${ }^{2}$ A common route for benzofuran synthesis is through ring-closure of ortho-substituted phenol derivatives (Scheme 1a). ${ }^{3}$ However, the phenol generally requires prefunctionalization (i.e., ortho-halogenated phenols I are required) and the approach proceeds by; i) attachment of the alkynyl/alkenyl chain via transition-metal-catalyzed crosscoupling (I to II); then, ii) transition-metal-catalyzed ring closure (II to III). More recently, efforts have targeted a more direct synthesis of benzofurans via $\mathrm{C}-\mathrm{H}$ coupling of simple phenols with alkenes and alkynes (Scheme 1b). ${ }^{4}$ Despite this tremendous progress, most reactions require the addition of transition metals and the development of routes to benzofurans that do not require such metals remains an important goal.

The trapping of nucleophiles by activated sulfoxides through interrupted Pummerer-type processes has begun to spawn a variety of useful transformations. ${ }^{5, \mathrm{x}}$ In particular, this mode of reactivity has allowed the facile transformation of $\mathrm{C}-\mathrm{H}$ bonds in the absence of transition metals. ${ }^{6}$ This mode of reactivity has recently been harnessed by Yorimitsu and co-workers for the synthesis of 2-methylthiobenzofurans by reaction of simple phenols with ketene dithioacetal monoxides (Scheme 1c). ${ }^{7,8}$

Scheme 1. (a), (b), (c) Current methods for the synthesis of benzofurans and (d) using sulfoxides for the divergent synthesis of benzothiophenes and benzofurans. TM = transition metal.

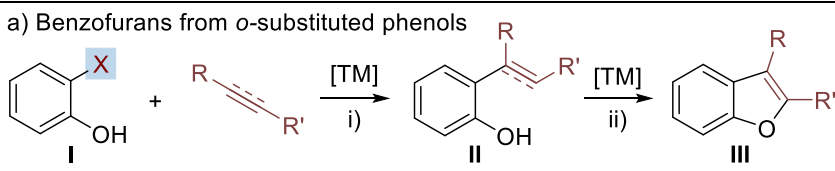

b) Benzofurans from simple phenols

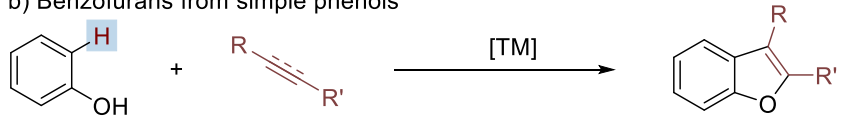

c) Benzofurans from simple phenols and ketene dithioacetal monoxides

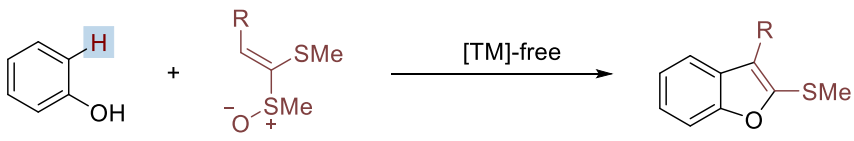

d) This work: benzofurans from simple phenols and benzothiophene S-oxides

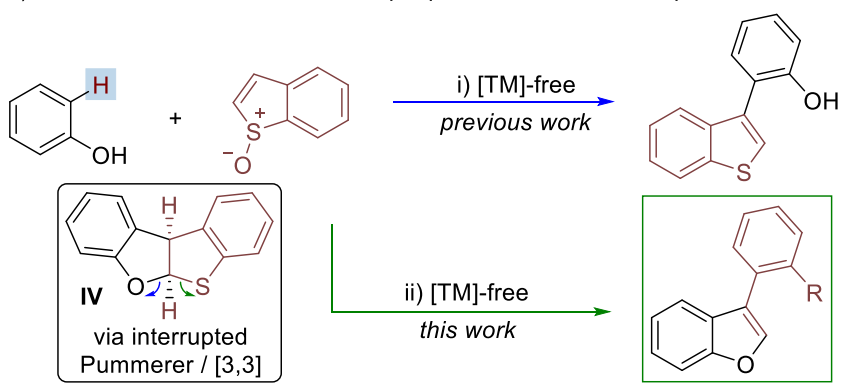

We have recently described the arylation of benzothiophene $S$ oxides, readily prepared from the parent benzothiophene by simple oxidation, via an interrupted Pummerer-type reaction (Scheme 1d, i). ${ }^{9}$ In this process, phenol substrates are captured by activated benzothiophene $S$-oxides before [3,3] sigmatropic rearrangement leads to the formation of the $S, O$-acetals $\mathbf{I V}$. Acid-mediated ring-opening of these intermediates then provides the $\mathrm{C} 3$-arylated benzothiophene through cleavage of the 
$\mathrm{C}-\mathrm{O}$ bond. This provides a novel route to functionalized benzothiophenes and, importantly, does not require the use of transition metal additives. In a proposed divergent approach, we speculated as to whether the intermediate thioacetals IV could also allow access to benzofuran derivatives through selective cleavage of the $\mathrm{C}-\mathrm{S}$ bond (Scheme 1d, ii)

Here we describe a transition metal-free synthesis of C3arylated benzofurans via the $\mathrm{C}-\mathrm{H}$ functionalization of simple phenol reagents. Our strategy represents a unique approach in which one molecule, the benzothiophene, is deconstructed for the assembly of another, the desired benzofuran. We also detail how the benzofuran products can undergo further derivatization through the use of desulfinylative cross-coupling methods. This procedure demonstrates that a variety of synthetically useful heterocyclic molecules can be constructed from simple phenols and previously unexploited benzothiophene $S$ oxides.

Scheme 2. (a) Preparation, isolation and X-ray crystallographic analysis of thioacetals $\mathbf{3 a}$ and thioacetal $S, S$-dioxides $\mathbf{4 a}$ and (b) one-pot synthesis of thioacetal $S, S$-dioxide $\mathbf{4 a}{ }^{\text {a }}$<smiles>[R]c1ccc(O)c([18F])c1</smiles>
$1 \quad[\mathrm{O}] \mathrm{L}_{-2}[\mathrm{~S}]=\mathrm{S}^{\prime}[\mathrm{S}]=\mathrm{S}^{+}-\mathrm{O}^{-}$
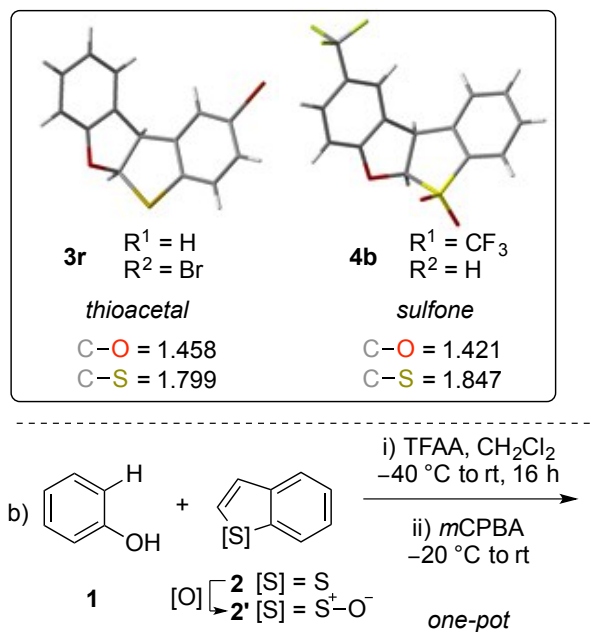

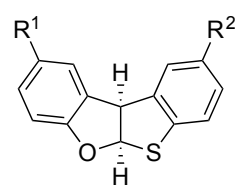

3a $R^{1}, R^{2}=H$ $60 \%$ (gram-scale)

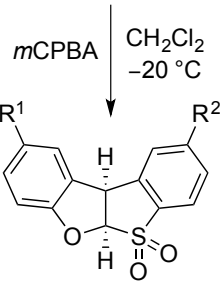

$4 a R^{1}, R^{2}=H$ $68 \%$ (gram scale) $41 \%$ overall yield from $1+2$

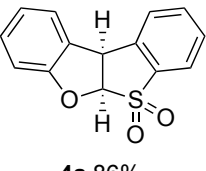

4a $86 \%$
${ }^{\text {a }}$ Reaction conditions- [O]: benzothiophene (1.0 equiv), $m$ CPBA (1.2 equiv), $\mathrm{BF}_{3} \cdot \mathrm{OEt}_{2}$ ( 8.0 equiv) then filtration. Sulfone formation: TFAA (1.5 equiv), phenol (1.5 equiv), then $m$ CPBA (2.4 equiv).

To begin our investigation we set about synthesizing the key thioacetal intermediate 3a (Scheme 2). Using our previously reported conditions we found that thioacetal $3 \mathbf{a}$ could be prepared through activation of the benzothiophene $S$-oxide 2' with trifluoroacetic anhydride (TFAA), then addition of phenol 1. This provided the thioacetal 3a in $60 \%$ isolated yield. The benzothiophene $S$-oxides 2' were easily prepared from the corresponding benzothiophenes $\mathbf{2}$. After oxidation of the benzothiophene $\mathbf{2}$, the crude material was filtered to provide the benzothiophene $S$-oxide 2' as a solution in $\mathrm{CH}_{2} \mathrm{Cl}_{2}$ suitable for use in subsequent steps. Importantly, isolation of the sulfoxide was not required.
Scheme 3. Scope of the one-pot synthesis of thioacetal $S, S$ dioxides. ${ }^{\mathrm{a}}$
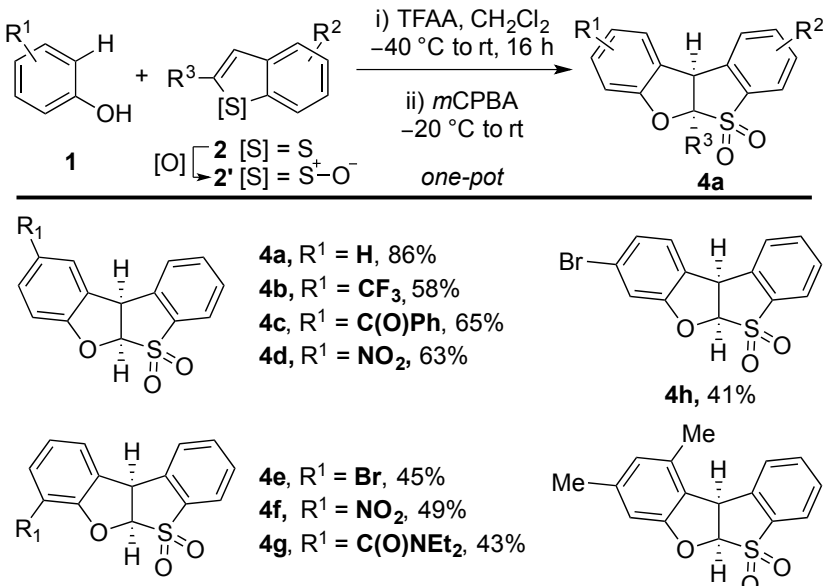

4e, $R^{1}=\mathbf{B r}, 45 \%$
$4 f, R^{1}=\mathbf{N O}_{2}, 49 \%$
$\mathbf{4 g}, R^{1}=\mathbf{C}(\mathbf{O}) \mathbf{N E t}_{2}, 43 \%$

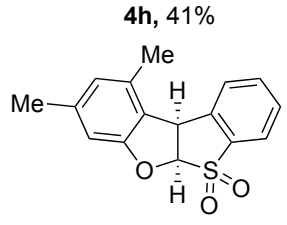

$4 i, 52 \%$

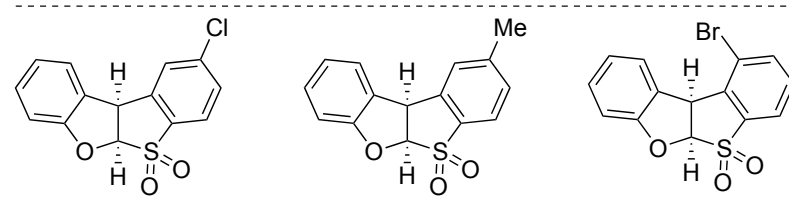

4j, $47 \%$

4k, $53 \%$

4I, $62 \%$

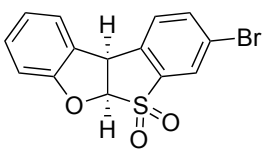

$4 \mathrm{~m}, 79 \%$

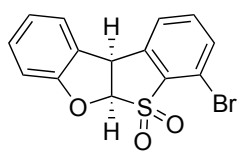

$4 n, 45 \%$

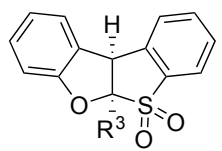

4o, $R^{3}=M e, 62 \%$

$4 \mathrm{p}, \mathrm{R}^{3}=\mathrm{Ph}, 66 \%$

$4 \mathrm{q}, \mathrm{R}^{3}=\mathrm{CO}_{2} \mathrm{Me}, 39 \%$
${ }^{a}$ Reaction conditions- [O]: benzothiophene (1.0 equiv), $m \mathrm{CPBA}$ (1.2 equiv), $\mathrm{BF}_{3} \cdot \mathrm{OEt}_{2}$ (8.0 equiv) then filtration. Sulfone formation: TFAA (1.5 equiv), phenol (1.5 equiv), then $m$ CPBA ( 2.4 equiv).

With the desired thioacetal in hand, we then considered methods for cleaving the $\mathrm{C}-\mathrm{S}$ bond in favor of the $\mathrm{C}-\mathrm{O}$ bond. From our previous report, we had observed cleavage of the $\mathrm{C}-$ $\mathrm{O}$ bond in the presence of acid, which led to the formation of C3-arylated benzothiophene products (Scheme 1d). ${ }^{9}$ Our strategy for selective cleavage of the $\mathrm{C}-\mathrm{S}$ bond was to first oxidize the thioacetal to the thioacetal $S, S$-dioxide. We hypothesized that converting the sulfide to the sulfone would render the $\mathrm{C}-\mathrm{S}$ bond more susceptible to bond cleavage. ${ }^{10}$ Upon treatment of thioacetal 3a with $m \mathrm{CPBA}$, the desired sulfone 4a was isolated in $68 \%$ yield. Both the thioacetal 3a and the sulfone $4 \mathbf{a}$ could also be prepared on a gram-scale without detriment to the yield.

The desired thioacetal $S, S$-dioxide 4 a could also be directly prepared from simple phenol and benzothiophene (Scheme 2b). Thus, following oxidation of benzothiophene $\mathbf{2}$ and filtration, benzothiophene $S$-oxide 2' was activated using TFAA before addition of the phenol to form the thioacetal 3a in situ. The addition of $m \mathrm{CPBA}$ to the same pot resulted in the formation of the desired thioacetal $S, S$-dioxide $4 \mathrm{a}$ in $86 \%$ overall yield. In general the one-pot procedure provided greater overall yields than the stepwise procedure.

With an efficient method for the preparation of sulfones 4 in hand we assessed the generality of this reaction. The yields 
provided in Scheme 3 are the result of the one-pot procedure, though we have also prepared and fully characterized each thioacetal intermediate $3 .^{11}$ A range of electron deficient phenols reacted well under the reaction conditions $(\mathbf{4 b}-\mathbf{4 h})$. Substituents in both the ortho and para positions of the phenol were tolerated, although the para-substituted phenols provided superior yields, likely due to less steric hindrance around the point of bond formation $(\mathbf{4 a}-\mathbf{4 g})$. When using metasubstituted

Scheme 4. Scope of the transition metal-free synthesis of benzofurans.
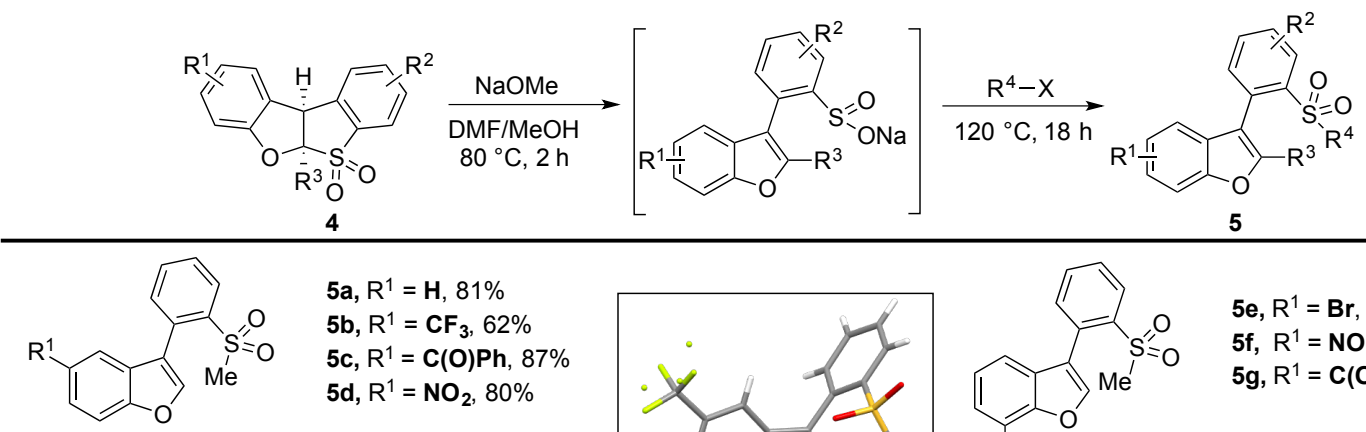

$$
5 \text { a, } R^{1}=\mathbf{H}, 81 \%
$$

5b, $\mathrm{R}^{1}=\mathrm{CF}_{3}, 62 \%$

5c, $R^{1}=\mathbf{C}(\mathrm{O}) \mathrm{Ph}, 87 \%$

5d, $\mathrm{R}^{1}=\mathrm{NO}_{2}, 80 \%$
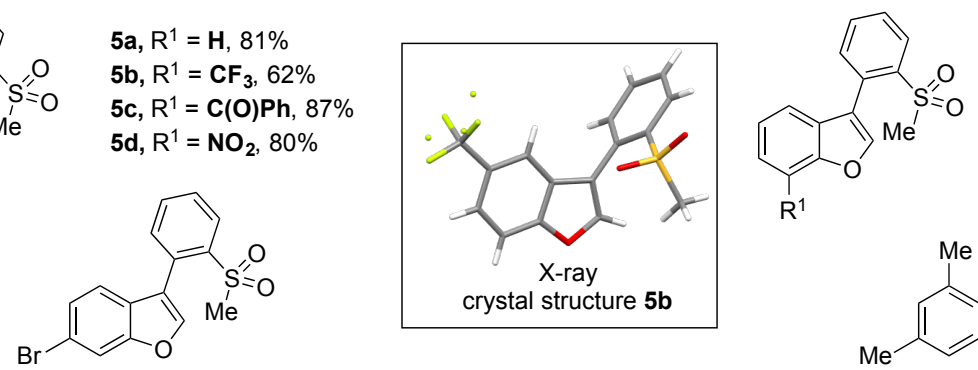

5e, $\mathrm{R}^{1}=\mathrm{Br}, 68 \%$

5f, $\mathrm{R}^{1}=\mathrm{NO}_{2}, 70 \%$

$\mathbf{5 g}, \mathrm{R}^{1}=\mathrm{C}(\mathrm{O}) \mathrm{NEt}_{2}, 65 \%$

5h, $75 \%$

$5 \mathbf{i}, 72 \%$
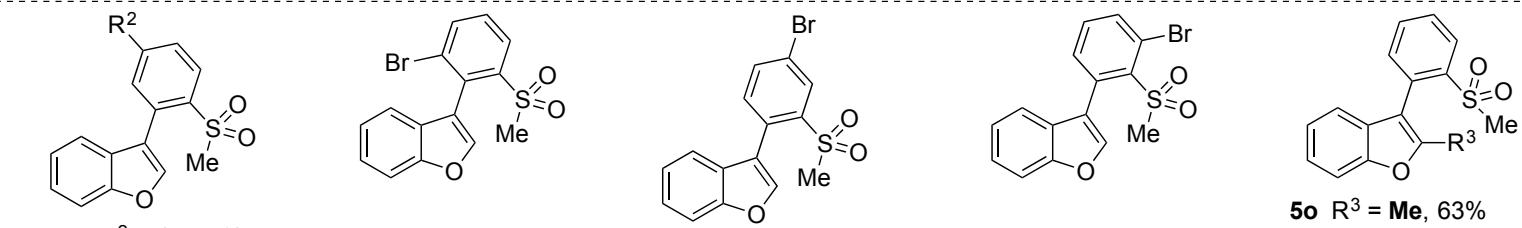

5j, $\mathrm{R}^{2}=\mathrm{Cl}, 80 \%$

5k, $R^{2}=$ Me, $52 \%$

5I, $72 \%$

$5 \mathrm{~m}, 52 \%$

5n, $54 \%$

5o $\mathrm{R}^{3}=\mathrm{Me}, 63 \%$

$5 p, R^{3}=\mathbf{P h}, 67 \%$

$5 q, R^{3}=\mathrm{CO}_{2} \mathrm{Me}, 62 \%$<smiles>O=S(=O)(Cc1ccccc1)c1ccccc1-c1ccccc1</smiles>

$5 r, 56 \%$ b,c

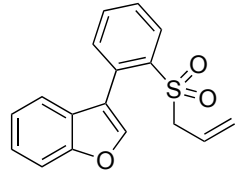

5s, $78 \%^{b}$

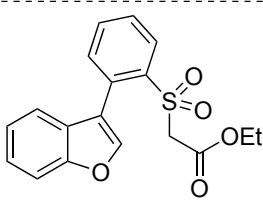

5t, $82 \%^{b}$

${ }^{\mathrm{a}}$ Reaction conditions: thioacetal $S, S$-dioxide 2 (1.0 equiv), NaOMe (1.5 equiv), MeI (1.5 equiv). ${ }^{\mathrm{b}} \mathrm{R}^{4}-\mathrm{X}$ (3.0 equiv). ${ }^{\mathrm{c}}{ }^{t} \mathrm{BuOK}$ used instead of $\mathrm{NaOMe}$.

phenols a mixture of regioisomeric products are formed, though the major isomer (4h) could be isolated in $41 \%$ yield. ${ }^{12}$ The least sterically crowded regioisomer is favored in this case. Phenols bearing electron-donating functional groups were poor substrates in this reaction, however, 3,5dimethylphenol gave a respectable yield of the desired sulfone $4 i$.

We also investigated the scope with respect to the benzothiophene $S$-oxide. As seen for the phenol substrates, a range of electron-donating and electron-withdrawing substituents were tolerated at each position (C4, C5, C6 and C7) of the benzothiophene $S$-oxide $(\mathbf{4 j}-\mathbf{4 n})$. The use of C2 substituted benzothiophene $S$-oxides led to thioacetal $S, S$-dioxides bearing a quaternary carbon center $(\mathbf{4 o}-\mathbf{4 q})$. The presence of electronreleasing methoxy groups on the benzene ring of the benzothiophene typically leads to less efficient arylation as the stability and electrophilicity of the activated $S$-oxide is reduced. ${ }^{9 a}$ In addition to halide substituents, we have previously shown that electron-withdrawing nitro groups are compatible with the arylation. $^{9 \mathrm{a}}$
Having investigated the generality of the procedure we now looked to collapse these structures to form the desired benzofuran products 5 . We proposed that the $\mathrm{C}-\mathrm{S}$ bond in the sulfone would be more susceptible to bond cleavage than the $\mathrm{C}-$ $\mathrm{O}$ bond upon treatment with base. Indeed, analysis of the bond lengths in the crystal structures of the thioacetal $3 \mathbf{r}$ and thioacetal $S, S$-dioxide $\mathbf{4 b}$ supported our hypothesis (Scheme 2). For example, the $\mathrm{C}-\mathrm{O}$ and $\mathrm{C}-\mathrm{S}$ bonds of the thioacetal $\mathbf{3 r}$ are 1.458 and 1.799 , respectively. Oxidation with $m$ CPBA resulted in the formation of thioacetal $S, S$-dioxide $\mathbf{4 b}$, which possesses a shorter $\mathrm{C}-\mathrm{O}$ bond (1.421) and a longer $\mathrm{C}-\mathrm{S}$ bond (1.847) compared to thioacetal 3r.

The addition of $\mathrm{NaOMe}$ resulted in the formation of the desired C3-arylated benzofuran products (Scheme 4). The sulfinate products were converted in situ to the corresponding sulfones by treatment with MeI. Using these conditions we transformed each of the sulfones (Scheme 3) to the corresponding benzofurans in good to very high yields. We were pleased to observe the formation of products bearing a halo group (5e, 5h, $\mathbf{5} \mathbf{j}, \mathbf{5} \mathbf{l}-\mathbf{5 n})$ as these would likely undergo com- 
peting reactions in more conventional approaches involving transition metal additives. Products 5o $-\mathbf{5 q}$ revealed that the C2 substituent, which initially resides on the benzothiophene substrate, can be efficiently transferred to the benzofuran. This allowed access to C2, C3-disubstituted benzofurans from simple phenol starting materials. We also demonstrated that a range of electrophiles other than MeI could be used to quench the sulfinate upon completion of the base-mediated bond cleavage event $(\mathbf{5 r}-\mathbf{5 t})$.

Based on previous reports, we have proposed a mechanism for the formation of the benzofuran products from benzothiophene and phenol (Scheme 5). ${ }^{9}$ The process begins with oxidation of the benzothiophene 2 to the benzothiophene $S$-oxide 2'. The phenol is then captured by the activated sulfoxide $\mathbf{V}$ in an interrupted Pummerer-type process. The resultant aryloxysulfonium salt VI then undergoes spontaneous [3,3] sigmatropic rearrangement and cyclisation to form the thioacetal intermediate 3. Oxidation of the thioacetal provides sulfone 4 , before addition of base gives access to the desired benzofuran products 5.

Scheme 5. Mechanism for the formation of benzofurans from phenols and benzothiophenes. Colors indicate one-pot processes.

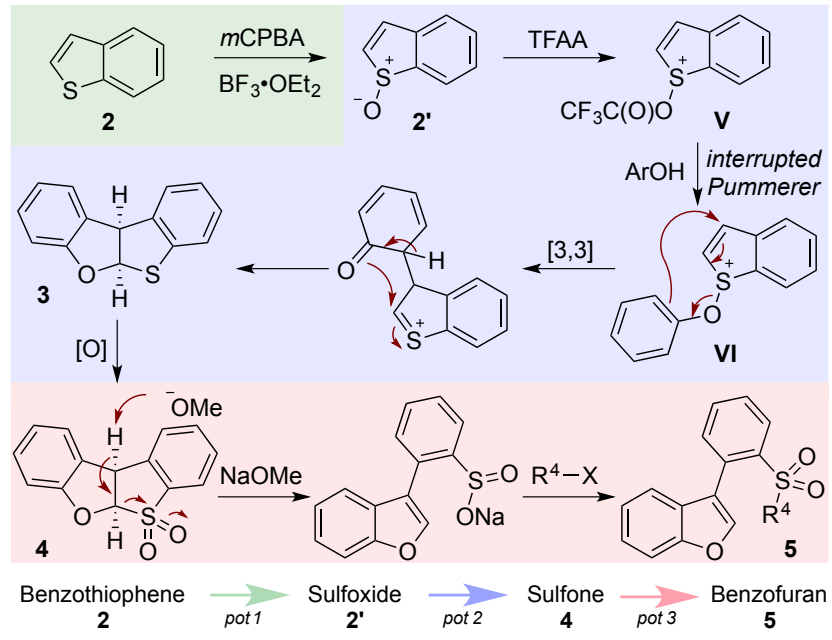

Scheme 6. Scope of the palladium-catalyzed desulfinative coupling of sulfones 4 with aryl bromides.

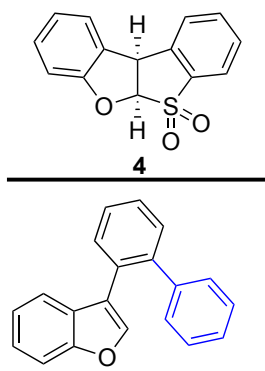

$6 a, 74 \%$

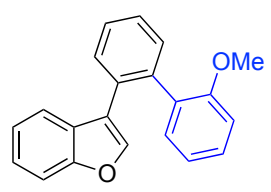

$6 d, 82 \%$
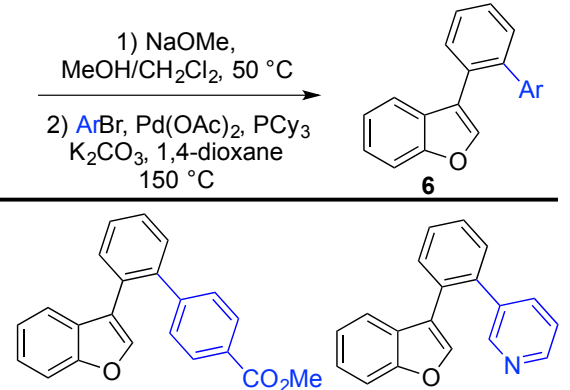

6b, $84 \%$

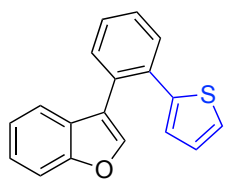

$6 e, 75 \%$
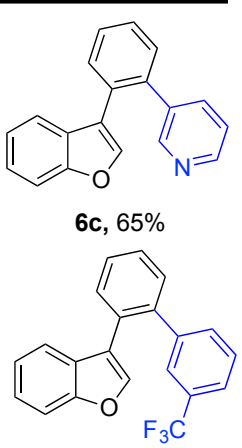

6f, $84 \%$ a Reaction conditions: thioacetal S,S-dioxide 2 (2.0 equiv), NaOMe (3.0 equiv), $\mathrm{Pd}(\mathrm{OAc})_{2}(10 \mathrm{~mol} \%), \mathrm{PCy}_{3}(20 \mathrm{~mol} \%) \mathrm{K}_{2} \mathrm{CO}_{3}$ (1.5 equiv), $\mathrm{ArBr}$ (1.0 equiv).

Sulfinate salts are a class of versatile compounds that have recently found use as coupling partners in palladium-catalyzed cross-coupling reactions. ${ }^{13}$ We therefore envisioned a subsequent desulfinative cross coupling of aryl halides with our sulfinate-containing benzofuran products. If successful, this would establish sulfoxides as a traceless activating group for $\mathrm{C}-\mathrm{H}$ functionalization in this method. Thus, the intermediate aryl sulfinates, formed from treatment of the sulfones 4 with base, underwent desulfinative palladium-catalyzed crosscoupling in the same pot to provide the desired biphenyl benzofurans 6 (Scheme 6). This procedure gave good to very high yields for all substrates tested. A range of aryl bromides were applicable including electron-deficient $(\mathbf{6 b}, \mathbf{6 f})$, electron-rich $(\mathbf{6 d})$, and heteroaromatic bromides $(\mathbf{6 c}, \mathbf{6 e})$. In addition, ortho, meta- and para-substituted $(\mathbf{6 b}, \mathbf{6 d}, \mathbf{6 f})$ substrates all gave similarly high yields. The formation of $\mathbf{6 d}$ was particularly impressive as it represents an efficient process for the crosscoupling of two sterically encumbered ortho-substituted reagents. ${ }^{14}$ We believe this displays the potential for accessing a range of substituted benzofuran derivatives from benzothiophene $S$-oxides and phenols. Importantly, no trace of the sulfoxide group that is present in the starting material remained upon formation of the product.

We have reported on the synthesis of benzofurans from simple phenol starting materials. The reaction utilizes the unique reactivity of benzothiophene $S$-oxides to promote the $\mathrm{C}-\mathrm{H}$ functionalization of phenols without the requirement for transition metal additives. The approach grants access to a variety of C3-arylated benzofurans that can also undergo further derivatization. In combination with our previous studies, we have shown that a common sulfoxide starting material provides selective access to $\mathrm{C} 3$-arylated benzothiophenes or $\mathrm{C} 3$ arylated benzofurans through a divergent strategy.

\section{ASSOCIATED CONTENT}

\section{Supporting Information}

The Supporting Information is available free of charge on the ACS Publications website.

\section{Corresponding Author}

* Email: david.j.procter@manchester.ac.uk

\section{Present Addresses}

$\uparrow$ School of Chemistry, University of Manchester, Oxford Road, Manchester, M13 9PL, UK.

\section{ORCID}

Kevin Yang: 0000-0002-8746-3862

Alexander P. Pulis: 0000-0003-1754-527X

Gregory J. P. Perry: 0000-0001-8173-3369

David J. Procter: 0000-0003-3179-2509

\section{Notes}

The authors declare no competing financial interest.

\section{ACKNOWLEDGMENT}

We thank the EPSRC (Established Career Fellowship to D.J.P.); the University of Manchester (Lectureship to A.P.P. and G.J.P.P). We thank the Manchester X-ray crystallography service. 


\section{REFERENCES}

1. For a general review on benzofuran synthesis and applications see: (a) Wu, J. Five-Membered Heterocycles: Benzofuran and Related Systems. In Modern Heterocyclic Chemistry; WileyVCH Verlag GmbH \& Co. KGaA: Weinheim, Germany, 2011; Vol. 1, pp 593-633. For bioactive benzofuran containing compounds see: (b) Khanam, H.; Shamsuzzaman. Bioactive Benzofuran Derivatives: A Review. Eur. J. Med. Chem. 2015, 97, 483-504. (c) Hiremathad, A.; Patil, M. R.; K. R., C.; Chand, K.; Santos, M. A.; Keri, R. S. Benzofuran: An Emerging Scaffold for Antimicrobial Agents. RSC Adv. 2015, 5, 96809-96828. (d) Asif, M. Mini Review on Important Biological Properties of Benzofuran Derivatives. J. Anal. Pharm. Res. 2016, 3, 48-51. (e) Heravi, M. M.; Zadsirjan, V.; Hamidi, H.; Tabar Amiri, P. H. Total Synthesis of Natural Products Containing Benzofuran Rings. RSC Adv. 2017, 7 (39), 24470-24521. For benzofurans in materials science see: (f) Tsuji, H.; Ilies, L.; Nakamura, E. Synthetic Strategy for Multisubstituted Fused Furan Compounds Using Main-Group Metal Reagents. Synlett 2014, 25, 2099-2110. (g) Tsuji, H.; Nakamura, E. Design and Functions of Semiconducting Fused Polycyclic Furans for Optoelectronic Applications. Acc. Chem. Res. 2017, 50, 396-406.

2. See ref 1a and Heravi, M. M.; Zadsirjan, V. Recent Advances in the Synthesis of Benzo[b]Furans. In Advances in Heterocyclic Chemistry; Elsevier Ltd, 2015; Vol. 117, pp 261-376.

3. Wu, X.-F.; Li, Y. Transition Metal-Catalyzed Benzofuran Synthesis, $1^{\text {st }}$ edition. In Transition Metal-Catalyzed Benzofuran Synthesis; Elsevier, 2017; pp 43-58.

4. For select procedures see: (a) Guo, X.; Yu, R.; Li, H.; Li, Z. Iron-Catalyzed Tandem Oxidative Coupling and Annulation: An Efficient Approach to Construct Polysubstituted Benzofurans. J. Am. Chem. Soc. 2009, 131, 17387-17393. (b) Wang, S.; Li, P.; Yu, L.; Wang, L. Sequential and One-Pot Reactions of Phenols with Bromoalkynes for the Synthesis of (Z)-2Bromovinyl Phenyl Ethers and Benzo[b]furans. Org. Lett. 2011, 13, 5968-5971. (c) Lee, D.-H.; Kwon, K.-H.; Yi, C. S. Dehydrative C-H Alkylation and Alkenylation of Phenols with Alcohols: Expedient Synthesis for Substituted Phenols and Benzofurans. J. Am. Chem. Soc. 2012, 134, 7325-7328. (d) Zeng, W.; Wu, W.; Jiang, H.; Huang, L.; Sun, Y.; Chen, Z.; Li, X. Facile Synthesis of Benzofurans via CopperCatalyzed Aerobic Oxidative Cyclization of Phenols and Alkynes. Chem. Commun. 2013, 49, 6611-6613. (e) Zhu, R.; Wei, J.; Shi, Z. Benzofuran Synthesis via Copper-Mediated Oxidative Annulation of Phenols and Unactivated Internal Alkynes. Chem. Sci. 2013, 4, 3706-3711. (f) Kuram, M. R.; Bhanuchandra, M.; Sahoo, A. K. Direct Access to Benzo[b]furans through Palladium-Catalyzed Oxidative Annulation of Phenols and Unactivated Internal Alkynes. Angew. Chem. Int. Ed. 2013, 52, 4607-4612. (g) Sharma, U.; Naveen, T.; Maji, A.; Manna, S.; Maiti, D. Palladium-Catalyzed Synthesis of Benzofurans and Coumarins from Phenols and Olefins. Angew. Chem. Int. Ed. 2013, 52, 12669-12673. (h) Agasti, S.; Maity, S.; Szabo, K. J.; Maiti, D. PalladiumCatalyzed Synthesis of 2,3-Disubstituted Benzofurans: An Approach Towards the Synthesis of Deuterium Labeled Compounds. Adv. Synth. Catal. 2015, 357, 2331-2338. (i) Agasti, S.; Sharma, U.; Naveen, T.; Maiti, D. Orthogonal Selectivity with Cinnamic Acids in 3-Substituted Benzofuran Synthesis through C-H Olefination of Phenols. Chem. Commun. 2015, 51, 5375-5378. Liu, L.; Ji, X.; Dong, J.; Zhou, Y.; Yin, S.-F. Metal-Free Oxidative Annulation of 2-Naphthols with Terminal Alkynes Affording 2-Arylnaphtho[2,1b]Furans. Org. Lett. 2016, 18, 3138-3141. (j) Udagawa, T.; Tsuchi, Y.; Takehara, I.; Kogawa, M.; Watanabe, H.; Yamamoto, M.; Tsuji, H.; Kawatsura, M. Palladium-Catalyzed Intermolecular Coupling of 2-Haloallylic Acetates with Simple Phenols, and Sequential Formation of Benzofuran Derivatives through the Intramolecular Cyclization. Tetrahedron 2017,
73, 6573-6579. (k) Abarghooei, M. A.; Mohebat, R.; KarimiJaberi, Z.; Mosslemin, M. H. Synthesis of 3-ArylBenzo[b]Furans and 3-Aryl-Naphtho[b]Furans Using $n$ Propyl-4-Aza-1-Azoniabicyclo[2.2.2]Octane Chloride Immobilised on $\mathrm{SiO} 2$ as an Efficient and Reusable Catalyst. $J$. Chem. Res. 2018, 42, 86-89. (1) Maji, A.; Reddi, Y.; Sunoj, R. B.; Maiti, D. Mechanistic Insights on Orthogonal Selectivity in Heterocycle Synthesis. ACS Catal. 2018, 8, 1011110118.

5. (a) Smith, L. H. S.; Coote, S. C.; Sneddon, H. F.; Procter, D. J. Beyond the Pummerer Reaction: Recent Developments in Thionium Ion Chemistry. Angew. Chem. Int. Ed. 2010, 49, 5832-5844. (b) Huang, X.; Klimczyk, S.; Maulide, N. Charge-Accelerated Sulfonium [3,3]-Sigmatropic Rearrangements. Synthesis 2012, 44, 175-183. (c) Yanagi, T.; Nogi, K.; Yorimitsu, H. Recent Development of Ortho-C-H Functionalization of Aryl Sulfoxides through [3,3] Sigmatropic Rearrangement. Tetrahedron Lett. 2018, 59, 2951-2959. For recent examples of the [3,3]-sigmatropic rearrangement of sulfonium salts derived from sulfoxides, see: (d) Yoshida, S.; Yorimitsu, H.; Oshima, K. 2-(2,2,2-Trifluoroethylidene)1,3-Dithiane Monoxide as a Trifluoromethylketene Equivalent. Org. Lett. 2009, 11, 2185-2188. (e) Kobatake, T.; Yoshida, S.; Yorimitsu, H.; Oshima, K. Reaction of 2-(2,2,2Trifluoroethylidene)-1,3-Dithiane 1-Oxide with Ketones under Pummerer Conditions and Its Application to the Synthesis of 3-Trifluoromethyl-Substituted Five-Membered Heteroarenes. Angew. Chem. Int. Ed. 2010, 49, 2340-2343. (f) Eberhart, A. J.; Imbriglio, J. E.; Procter, D. J. Nucleophilic Ortho Allylation of Aryl and Heteroaryl Sulfoxides. Org. Lett. 2011, 13, 5882-5885. (g) Eberhart, A. J.; Cicoira, C.; Procter, D. J. Nucleophilic Ortho -Allylation of Pyrroles and Pyrazoles: An Accelerated Pummerer/Thio-Claisen Rearrangement Sequence. Org. Lett. 2013, 15, 3994-3997. (h) Peng, B.; Huang, X.; Xie, L.-G.; Maulide, N. A Brønsted Acid Catalysed Redox Arylation, Angew. Chem. Int. Ed. 2014, 53, 8718-8721. (i) Yanagi, T.; Otsuka, S.; Kasuga, Y.; Fujimoto, K.; Murakami, K.; Nogi, K.; Yorimitsu, H.; Osuka, A. MetalFree Approach to Biaryls from Phenols and Aryl Sulfoxides by Temporarily Sulfur-Tethered Regioselective C-H/C-H Coupling. J. Am. Chem. Soc. 2016, 138, 14582-14585. (j) Kaldre, D.; Klose I.; Maulide N. Sterodivergent synthesis of 1,4-dicarbonyls by traceless charge-accelerated sulfonium rearrangement. Science, 2018, 361, 664-667; (k) Baldassari, L. L.; Mantovani, A. C.; Senoner, S.; Maryasin, B.; Maulide, N.; Lüdtke, D. S. Redox-Neutral Synthesis of Selenoesters by Oxyarylation of Selenoalkynes under Mild Conditions, Org. Lett. 2018, 20, 5881-5885. (1) Šiaučiulis, M.; Sapmaz, S.; Pulis, A. P.; Procter, D. J. Dual Vicinal Functionalisation of Heterocycles via an Interrupted Pummerer Coupling/[3,3]Sigmatropic Rearrangement Cascade. Chem. Sci. 2018, 9, 754-759. For a recent example of [2,3]-sigmatropic rearrangements of sulfonium salts derived from sulfoxide, see: (m) Hu, G.; Xu, J.; Li, P. Sulfur Mediated Propargylic C-H Alkylation of Alkynes. Org. Chem. Front. 2018, 5, $2167-$ 2170.

6. Pulis, A. P.; Procter, D. J. C-H Coupling Reactions Directed by Sulfoxides: Teaching an Old Functional Group New Tricks. Angew. Chem. Int. Ed. 2016, 55, 9842-9860.

7. (a) Kobatake, T.; Fujino, D.; Yoshida, S.; Yorimitsu, H.; Oshima, K. Synthesis of 3-Trifluoromethylbenzo[b]Furans from Phenols via Direct Ortho Functionalization by Extended Pummerer Reaction. J. Am. Chem. Soc. 2010, 132, 1183811840. (b) Murakami, K.; Yorimitsu, H.; Osuka, A. Practical, Modular, and General Synthesis of Benzofurans through Extended Pummerer Annulation/Cross-Coupling Strategy. Angew. Chem. Int. Ed. 2014, 53, 7510-7513. (c) Murakami, K.; Yorimitsu, H.; Osuka, A. Two-Step, Practical, and DiversityOriented Synthesis of Multisubstituted Benzofurans from Phenols through Pummerer Annulation Followed by CrossCoupling. Bull. Chem. Soc. Jpn. 2014, 87, 1349-1366. (d) 
Okamoto, K.; Hori, M.; Yanagi, T.; Murakami, K.; Nogi, K.; Yorimitsu, H. Sigmatropic Dearomatization/Defluorination Strategy for $\mathrm{C}-\mathrm{F}$ Transformation: Synthesis of Fluorinated Benzofurans from Polyfluorophenols. Angew. Chem. Int. Ed. 2018, 1-6. For a related procedure see: (e) Parnes, R.; Reiss, H.; Pappo, D. $\mathrm{Cu}(\mathrm{OTf})_{2}$-Catalyzed Pummerer Coupling of $\beta$ Ketosulfoxides. J. Org. Chem. 2018, 83, 723-732.

8. Murakami, K.; Yorimitsu, H.; Osuka, A. Practical and Scalable Syntheses of Substituted Ketene Dithioacetal Monoxides. Bull. Chem. Soc. Jpn. 2013, 86, 1193-1195.

9. (a) Shrives, H. J.; Fernández-Salas, J. A.; Hedtke, C.; Pulis, A. P.; Procter, D. J. Regioselective Synthesis of C3 Alkylated and Arylated Benzothiophenes. Nat. Commun. 2017, 8, 14801. (b) He, Z.; Shrives, H. J.; Fernández-Salas, J. A.; Abengózar, A.; Neufeld, J.; Yang, K.; Pulis, A. P.; Procter, D. J. Synthesis of C2 Substituted Benzothiophenes via an Interrupted Pummerer/[3,3]-Sigmatropic/1,2-Migration Cascade of Benzothiophene S-Oxides. Angew. Chem. Int. Ed. 2018, 57, 5759-5764. For related procedures see: (c) Eberhart, A. J.; Procter, D. J. Nucleophilic Ortho-Propargylation of Aryl Sulfoxides: An Interrupted Pummerer/Allenyl Thio-Claisen Rearrangement Sequence. Angew. Chem. Int. Ed. 2013, 52, 4008-4011. (d) Eberhart, A. J.; Shrives, H. J.; Álvarez, E.; Carrër, A.; Zhang, Y.; Procter, D. J. Sulfoxide-Directed Metal-Free Ortho -Propargylation of Aromatics and Heteroaromatics. Chem. Eur. J. 2015, 21, 7428-7434. (e) Eberhart, A. J.; Shrives, H.; Zhang, Y.; Carrër, A.; Parry, A. V. S.; Tate, D. J.; Turner, M. L.; Procter, D. J. Sulfoxide-Directed MetalFree Cross-Couplings in the Expedient Synthesis of Benzothiophene-Based Components of Materials. Chem. Sci. 2016, 7, 1281-1285. (f) Fernández-Salas, J. A.; Eberhart, A.
J.; Procter, D. J. Metal-Free CH-CH-Type Cross-Coupling of Arenes and Alkynes Directed by a Multifunctional Sulfoxide Group. J. Am. Chem. Soc. 2016, 138, 790-793.

10. We also attempted $\mathrm{C}-\mathrm{S}$ bond cleavage of the thioacetal 3 through the addition of $N$-iodosuccinimide (NIS), however, the desired benzofuran product was not observed. Veeneman, G. H.; van Leeuwen, S. H.; van Boom, J. H. Iodonium Ion Promoted Reactions at the Anomeric Centre. II An Efficient Thioglycoside Mediated Approach toward the Formation of 1,2-Trans Linked Glycosides and Glycosidic Esters. Tetrahedron Lett. 1990, 31, 1331-1334. Attempted cleavage of the $\mathrm{C}-\mathrm{S}$ bond in thioacetal 3 using MeOTf also failed to give the desired benzofuran product.

11. See the Supporting Information for the synthesis and characterisation of the thioacetal intermediates.

12. After the first step, the thioacetal 3 could be isolated in $73 \%$ yield as a $74: 26$ regioisomeric mixture $(\mathbf{3 h} / \mathbf{3 h}$ '). The minor thioacetal $S, S$-dioxide regioisomer $\mathbf{4 h}$ ' was not isolated.

13. (a) Ortgies, D. H.; Hassanpour, A.; Chen, F.; Woo, S.; Forgione, P. Desulfination as an Emerging Strategy in PalladiumCatalyzed C-C Coupling Reactions. Eur. J. Org. Chem. 2016, 2016, 408-425; (b) Markovic, T.; Rocke, B. N.; Blakemore, D. C.; Mascitti, V.; Willis, M. C. Pyridine Sulfinates as General Nucleophilic Coupling Partners in Palladium-Catalyzed Cross-Coupling Reactions with Aryl Halides. Chem. Sci. 2017, 8, 4437-4442.

14. Lundgren, R. J.; Stradiotto, M. Addressing Challenges in Palladium-Catalyzed Cross-Coupling Reactions Through Ligand Design. Chem. Eur. J. 2012, 18, 9758-9769. 